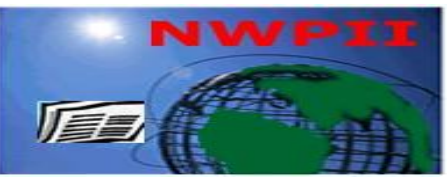

American Journal of Biomedical Sciences

ISSN: 1937-9080

nwpii.com/ajbms

\title{
Investigation of Hibiscus Sabdariffa (Roselle) as Histological Stain and in Assessment of Bar Bodies
}

\author{
Omorodion, Nosa Terry ${ }^{1,2 *}$, Achukwu , Peter $\mathbf{U}^{2}$ \\ ${ }^{1}$ Health Services Department, University of Benin, Benin City, Nigeria. \\ ${ }^{2}$ Department of Medical Laboratory science, Faculty of Health sciences and Technology, Univerisity of Nigeria, \\ Nsukka, Nigeria. \\ "Corresponding Author \\ Omorodion, Nosa Terry \\ University of Benin \\ Benin City \\ Nigeria \\ Department of Medical Laboratory science \\ Faculty of Health sciences and Technology \\ Univerisity of Nigeria \\ Nsukka \\ Nigeria \\ Cell no. +08136742270. \\ Email: terry.omorodion@uniben.edu
}

Received: 9 October 2016; | Revised: 15 February 2017; | Accepted: 21 February 2017

\begin{abstract}
A dye is a substance which is used for coloration. Dyes have been in use for ages, nowadays there are several kinds of dyes used in printing, textiles, food, leather and paints industries. They are also used in Histopathology and cytological examination. This study aims at demonstrating specific component of the cells that will be useful in diagnosis. Solution 1 stains Nuclei- dark blue to black, Cytoplasm stains dark brown to pink fibres-dark brown. The structures were weakly demonstrated by Roselle solution 1. Solution 2 stains Nuclei-dark blue to brown, Cytoplasm-golden brown, RBC-brown, Collagen fibres-golden brown. There was good demonstration of those structures. Roselle Solution 3 stains Nuclei-red, Cytoplasm-golden yellow, RBC-brown, Collagen fibres-pale blue. There was optimal demonstration of those structures. Roselle solution 4 stains Nuclei-red, Cytoplasm-golden yellow, RBC-brown, Collagen fibres-golden yellow, Roselle solution 5 stains Nuclei-blue Cytoplasm-pink. It gives the same color as haematoxylin and eosin technique. Buccal smear and blood smear stains with Roselle plant extract and eosin Nuclei-Blue, Cytoplasm-pink, Barr body- not seen. Conclusively, Roselle plant has the ability to stain tissue sections and staining intensity depends on the type of mordant used.
\end{abstract}

Keywords: Rosellle, Hibiscus sabdariffa Linn, alcohol 


\section{Introduction}

A dye is a substance which is used for coloration. Dyes have been in use for ages, nowadays there are several kinds of dyes used in printing, textiles, food, leather and paints industries. They are also used in Histopathology and biology. Dyes may be natural if they are derived from plants and animals, and they could be synthetic if they are derived from coals. Some histological dyes are natural Histological dyes are substance, which is use to color tissues in order to aid optical differentiation [1,2]. The hematoxylin stains the acidic components of the cell (nucleus), giving them dark violet or blue color. The Eosin stains the basic components of the cell (cytoplasm), giving them pink color [3]. Hibiscus sabdariffa is a plant cultivated in many countries in the world; Sudan is one of these countries [4]. Little research explored the staining potentials of Hibiscus sabdariffa as a substitution of eosin in H\&E staining method [5].

Roselle plant is a medicinal plant around the world. 80 percent of ethanol Roselle is use antigenic and chemo-preventive activity in colon carcinogenesis model. Roselle tea extract was described to have high inhibitory activity against porcine pancreatic alpha-amylase [1]. Roselle juice was worked on and it was discovered that the urine after consumption of Rosselle juice contain decrease in creatinine, uric acid, citrate, tartrates, calcium, sodium, potassium and phosphate but does not have effect on oxalate in excretion of urine [1,6]. Hibiscus sabdariffa extract was used as local drink is medicinal and contain antioxidant effect [7]. This work is aimed at introducing a natural dye for histopathological diagnosis, which is original. It is aim at demonstrating specific component of the cells that will be useful in diagnosis. The dye is extracted from a plant called Roselle (Hibiscus sabdariffa linn), this dye is readily available and also very affordable because it can be cultivated seasonally on any land and does not need so much care.

\section{Material and Method}

Standard method of extraction was used in the course of this investigation. The materials were purchased at Patanne Chemicals, 124, Sapele road, Benin city, Edo state, Nigeria. The leaves were collected, washed and cleaned properly and place in a flat bottom flask before application of heat. To obtained the boiled decoction $1 \mathrm{~L}$ of distilled water was added to 500 $\mathrm{g}$ of freshly collected leaves of Roselle plant and allow to heat for 20 minutes, using gas cooker. After the extraction is done by heat, the decoction was left to cool and filtered using Whatman No 1 filter paper and was kept in a refrigerator at 4 degree centrigrade for the period of the research. The leaves of Roselle plant was collected and dried under shade and grounded into powder. The powder $(200 \mathrm{~g})$ were collected and macerated in $70 \%$ ethanol at room temperature in 24 hours. It was then filtered using Whatman No 1 filter paper. Solution 1 was prepared from Roselle powder, glacial acetic acid in 30\% alcohol, solution 2 was prepared with Roselle powder macerated in iron alum and 30\% alcohol, solution 3 was prepared with Roselle macerated in 5 percent potassium alum and 30 percent alcohol, Roselle solution 4 was prepared with Roselle powder 5 percent iron, 1 percent glacial acetic acid and 30 percent alcohol stained, Roselle solution 5: Fresh Roselle extract plus eosin as counter stain. Skin and muscle tissues were taken and processed with automated tissue processor and stained with various Roselle solutions, the slide were viewed microscopically and photomicrographs were taken.

\section{Results}

Solution 1 stains Nuclei-dark blue to black, Cytoplasm stains dark brown to pink fibres-dark brown. The structures were weakly demonstrated by Roselle solution 1 . Solution 2 stains Nucleidark blue to brown, Cytoplasm-golden brown, RBC-brown, Collagen fibres-golden brown. There was good demonstration of those structures. Roselle Solution 3 stains Nuclei-red, Cytoplasm-golden yellow, RBC-brown, Collagen 
fibres-pale blue. There was optimal demonstration of those structures. Roselle solution 4 stains Nuclei-red, Cytoplasm-golden yellow, RBC-brown, Collagen fibres-golden yellow. Roselle solution 5 stains Nuclei-blue Cytoplasm-pink. It gives the same color as haematoxylin and eosin. Buccal smear and blood smear stains with Roselle plant extract and eosin Nuclei-Blue, Cytoplasm-pink, Barr body- not seen.

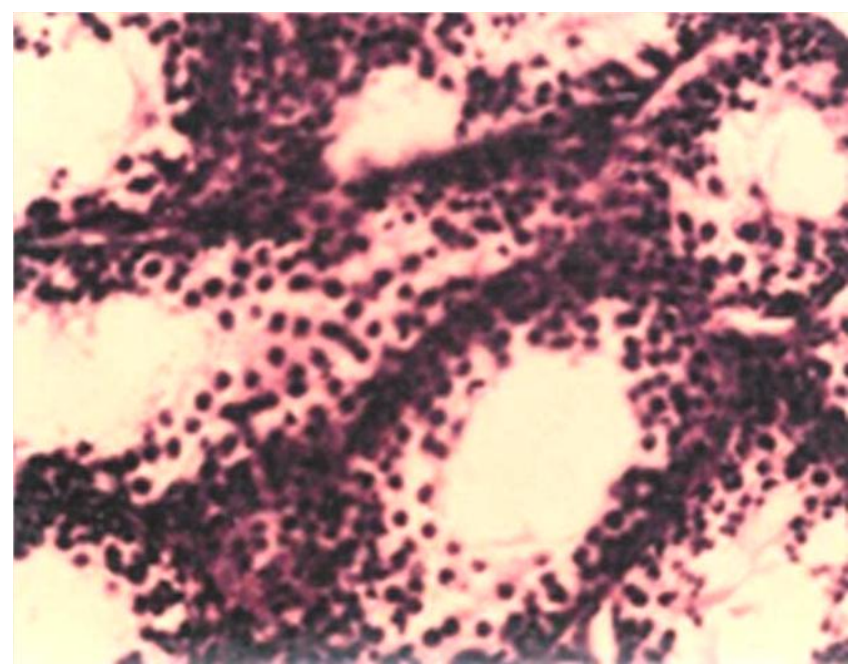

Figure 1: Tissue with poor optical differentiation stain with Roselle plant. x400 magnification.

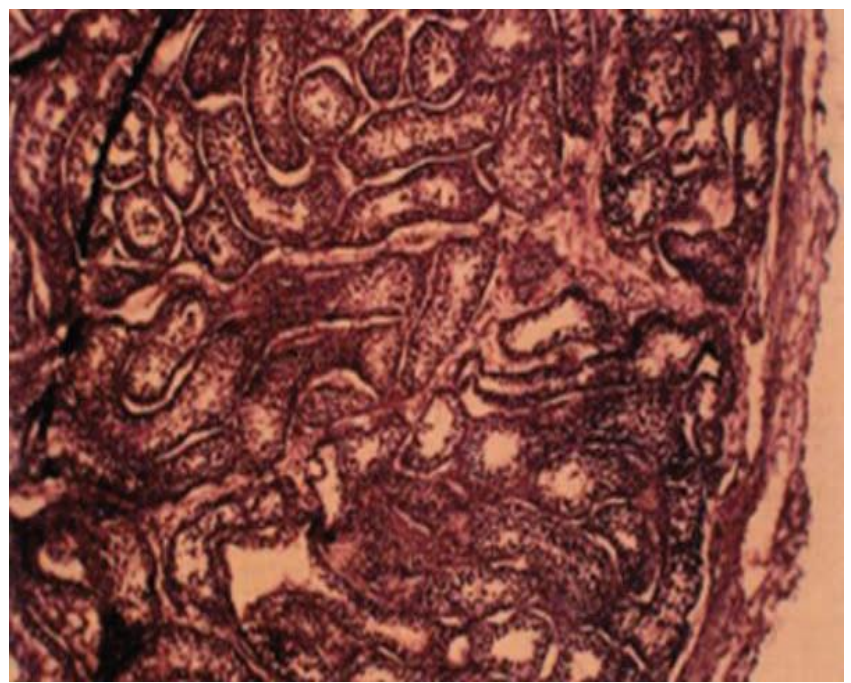

Figure 2: Tissue with good optical differentiation stain with Roselle plant enhanced with iron alum. x400 magnification.

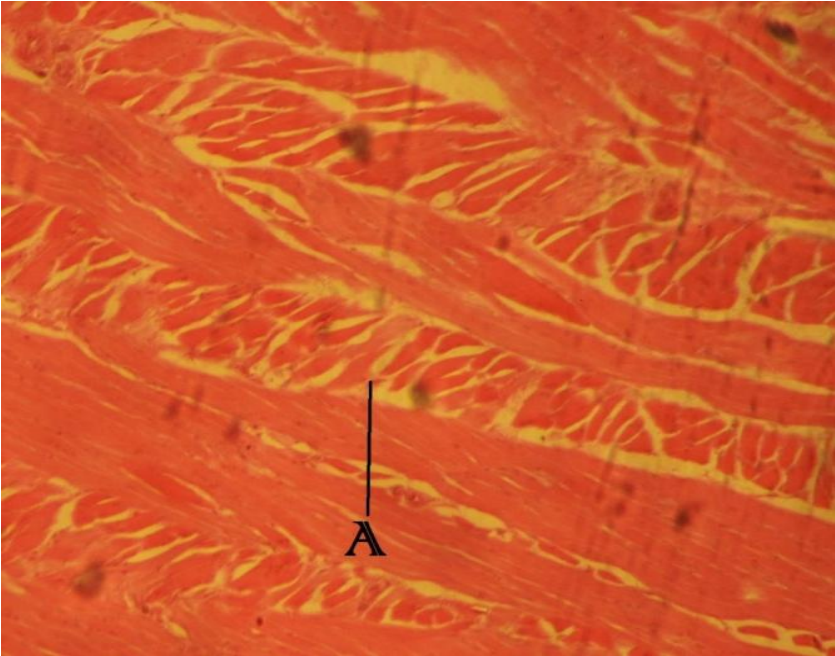

Figure 3: Intercalated disc of normal muscle tissue after the use of Roselle solution 3. x400 magnification.

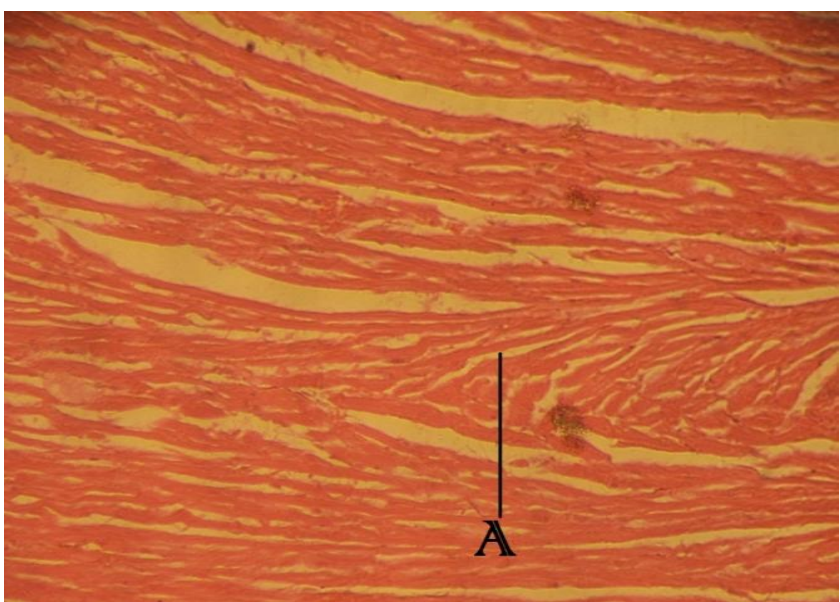

Figure 4: Striation (A) of normal muscle tissue after the use of Roselle solution 4. x400 magnification.

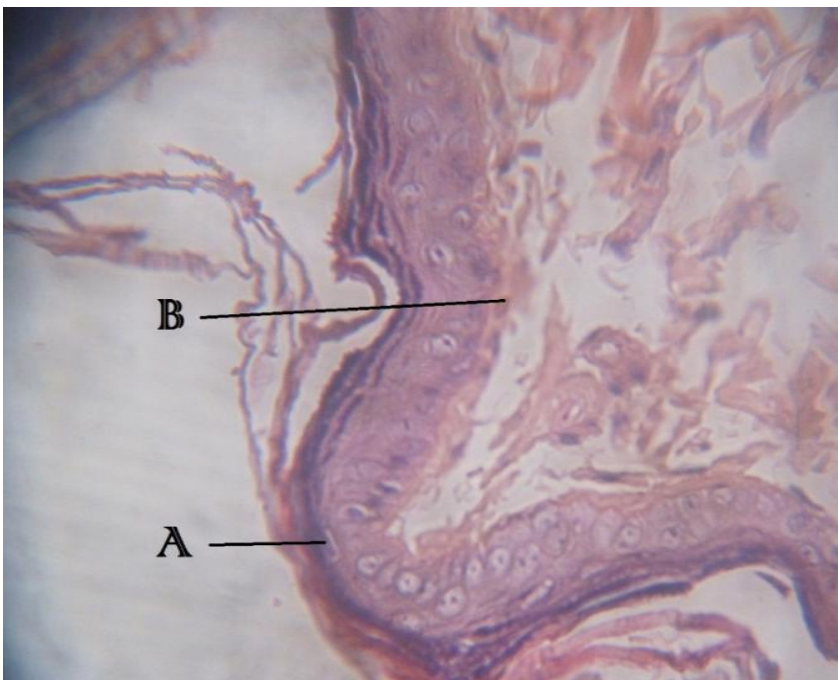

Figure 5: Dermis and Epidermis (A and $\mathrm{B}$ ) respectively of skin tissue. After use of crude extract of Roselle plant with eosin. x400 magnification. 


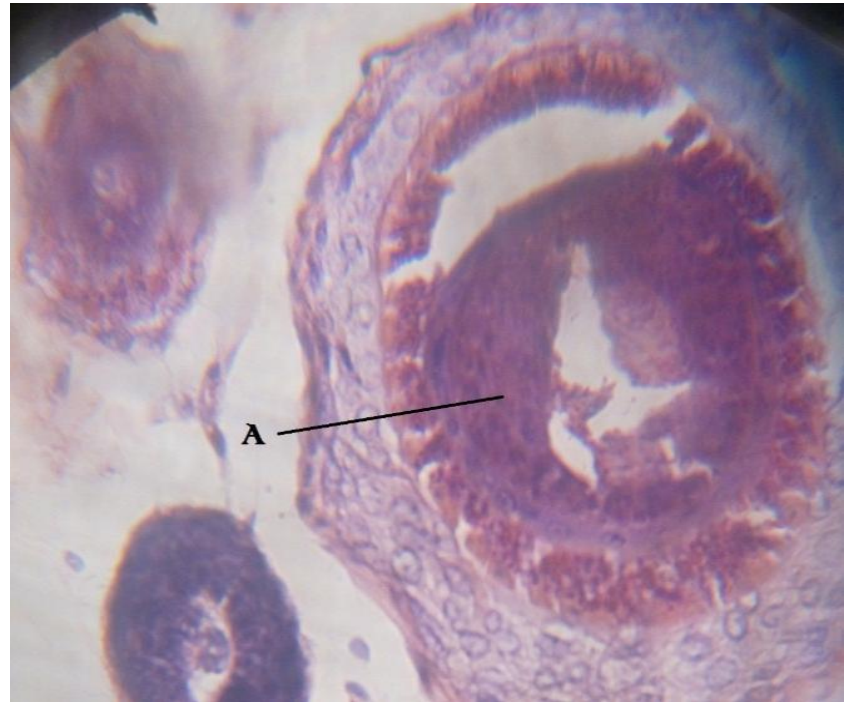

Figure 6: Hair follicle (A) of skin stain with H\&E. Control slide with $\mathrm{x} 400$ magnification.

\section{Discussion}

Roselle (Hibiscus Sabdariffa Linn) extract dissolved in all the solvents used in this work. The solubility in alcohol was higher than solubility in water. Section stained with different solutions of Roselle extract imparted color on the section. Sections stained with aqueous solution were colored faint brown, golden yellow and golden brown color microscopically. When used as primary with eosin as counter stain it produces the same color contrast as haematoxylin, meaning we can have Roselle extract and Eosin technique. Roselle extraction an acidic $\mathrm{pH}$ but addition of iron alum increased the $\mathrm{PH}$ to alkaline, therefore been able to stain in both acidic alkaline solutions. The use of iron alum as mordant with Roselle extraction the section of the test showed a good nuclear/cytoplasmic differentiation as observed with the potassium alum, but in this case more clearly demonstrated. The increased nuclear/cytoplasmic differentiation and demonstration of other connective tissue can be ascribed to the evidences that iron alum tends to form a stronger dye- lake bond than potassium alum.

\section{Conclusion}

Conclusively, Roselle plant has the ability to stain tissue sections and staining intensity depends on the type of mordant used.

\section{References}

1. Chewonarin, T., Kinouchi, T., kataoka, K, Arimachi, H., Kuwahara, T., Initkekumnuen, U. and Ohnishi, Y. 1999. Effect of Roselle (Hibiscus sabdariffa Linn), a thai medicinal plant, on the mutagenicity of various known mutagens in Salmonella typhimurium and on formation of Aberrant Crypt Foci induced by the colon carcinogens Azoxymethane and 2Amino-1 Methyl-6-phenyllimidazo (4, 5-b) pyridine in F344 rats. Food Chemical and Toxicology,37;591601. DOI: 10.1016/S0278$\underline{6915(99) 00041-1}$

2. Sofowora A., (1993). Phtochemical screening of medicinal plants and traditional medicine in africa, 2nd edition. Spectrum books ltd. Nigeria pp. 150-156. www.eajournals.org/wpcontent/uploads/Growth-and-NutritionalQualities-of-Three-Ocimum-Species-AsAffected-By-Methods-of-Propagation.pdf

3. Godwin Avwioro. Histochemical Uses of Hematoxylin, a Review. JPCS, 2011; 1:2434.https://www.statperson.com/Journal/Scien ceAndTechnology/Article/Volume19Issue3/1 9_3_7.pdf

4. Bahaeldeen Babiker Mohamed, Abdelatif Ahmed Sulaiman and Abdelhafiz Adam Dahab. Roselle (Hibiscus Sabdariffa L.) in Sudan, Cultivation and Their Uses. Bull. Environ. Pharmacol. Life Sci., 2012; 1 (6): 48 54.http://www.ajol.info/index.php/star/article/ viewFile/112803/102550

5. Abd-Alhafeez Ibnouf, Khalid Adam, Esam AbdulRaheem, and Ali Ageep. Staining of histological sections from the small intestine using Hibiscus Sabdariffa. Journal of Biomedical and Pharmaceutical Research, 2014;3(5):0103.http://www.usajournals.com/ wpcontent/uploads/2015/04/Raheem_Vol35.p df 
6. Kirdpon, S.S.N., Nakorn and W. kirdpon, (1994). Changes in urinary chemical composition in healthy volunteers after consuming Roselle (Hibiscus sabdariffa Linn) juice, J Med assoc. Thailand; 779(6):314

7. Tseng, TH, Kaoes, Chucy, Choufp, Lin wu TIHW., Wang CJ.(1997) Protective effect of dried flower extracts of Hibiscus sabdariffa against oxidative stress in rat primary hepatocytes. Food Chem. Toxicology. 35:11591164. DOI: $\quad$ 10.1016/S0278$\underline{6915(97) 85468-3}$ 